\title{
THE LIQUEFACTION OF HELIUM
}

Dirk van Delft,

Museum Boerhaave and Leiden University, The Netherlands

○ $\mathrm{n}$ the day that Heike Kamerlingh Onnes liquefied helium, Leiden briefly became the coldest place on earth. It was the $10^{\text {th }}$ of July 1908 , a wet and windy day shortly before the summer holidays. Onnes, awakened before dawn by his wife Betsy (known as Bé), ordered a carriage at 5 a.m. to take him from Huize ter Wetering, his fine country house on the river Galgewater, to Steenschuur. There, in the city centre, opposite Van der Werff Park, stood the Physics Laboratory over which he presided. Since his arrival in 1882 he had committed himself with vision and perseverance to setting up a cryogenic laboratory, and on this $10^{\text {th }}$ day of July, the anniversary of his doctorate, he would attempt to move another step closer to absolute zero [1].

Kamerlingh Onnes donned his white coat as soon as he arrived at the laboratory. His technicians, led by master instrument maker Gerrit Jan Flim, were already hard at work. The day before, they had increased the stock of liquid air to 75 litres, and together with Onnes they had checked the apparatus for leakages, pumped it vacuum, and then filled it with pure gas [2]. Now, in the early morning, the first task was to liquefy the hydrogen. While the pumps thundered away in lab Aa - the hydrogen apparatus had been in use since the spring of $1906-$ Onnes and his assistants rushed around turning taps, connecting and disconnecting gas cylinders, and keeping an eagle eye on pressure gauges and thermometers. They did not stop for lunch. By 1.30 p.m., 20 litres of liquid hydrogen had been tapped into vacuum or 'Dewar' flasks, enough to launch the attack on helium in the adjoining room, lab E'.

\section{Halfium}

Onnes was less than optimistic about his chances of success; his previous attempt to subdue the last of the 'permanent' gases, in February, had been a fiasco. He had identified a flaky white cloud of material as solid helium, concluding that rapid expansion evidently caused the helium to change straight from a gas into a solid, like carbonic acid foam from a fire extinguisher. Elated, he had telegraphed James Dewar, his main rival in London, that the race was over: 'Converted helium into solid' [3]. The Nieuwe Rotterdamsche Courant of March 13 reported that Onnes's achievement had been widely covered in the international press. Somewhat delayed (and mangled), the news reached the west coast of the United States. 'Helium is Liquefied by German Professor' wrote the San Francisco Examiner the following day. 'Metal Heretofore Known Only as a Gas Reduced by Kammerlin Onnes at University of Leyden.'

All too soon, however, it became apparent that Leiden's exultation had been premature. On further inspection the little cloud turned out to be hydrogen, which had been left behind in the helium as an unforeseen contaminant and had frozen during the cooling process. The students jeeringly referred to 'halfium', a joke that Onnes did not much appreciate (note that 'heel is Dutch for -

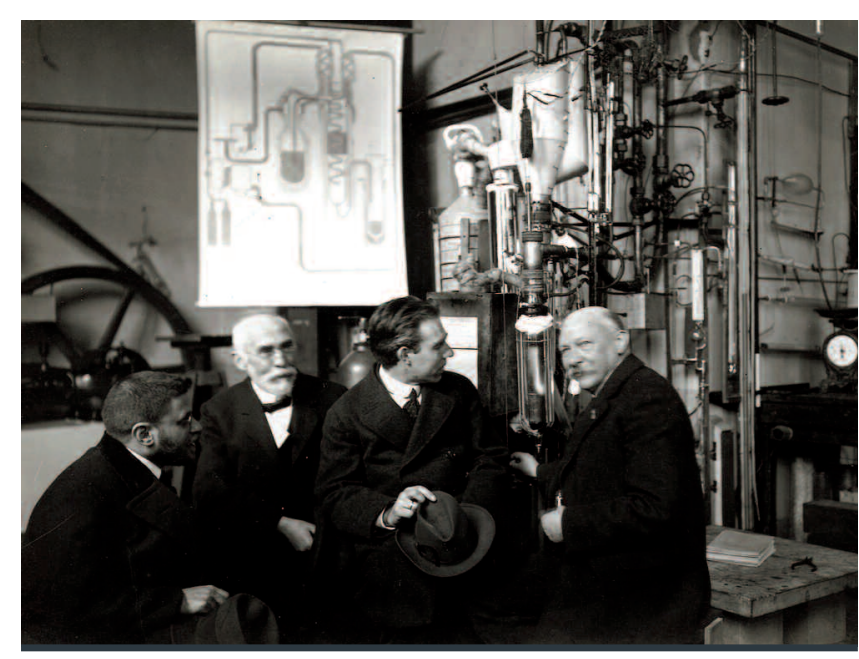

$\triangle$ FIG. 1: After the liquefaction of helium, the Leiden cryogenic laboratory attracted a lot of foreign visitors. From left to right: Paul Ehrenfest, Hendrik Antoon Lorentz, Niels Bohr and Heike Kamerlingh Onnes at the helium liquefier, 1919. @ Photo Museum Boerhaave, Leiden

V FIG. 2: The 1908 Leiden helium liquefier, now in Museum Boerhaave, Leiden. @ Photo Museum Boerhaave

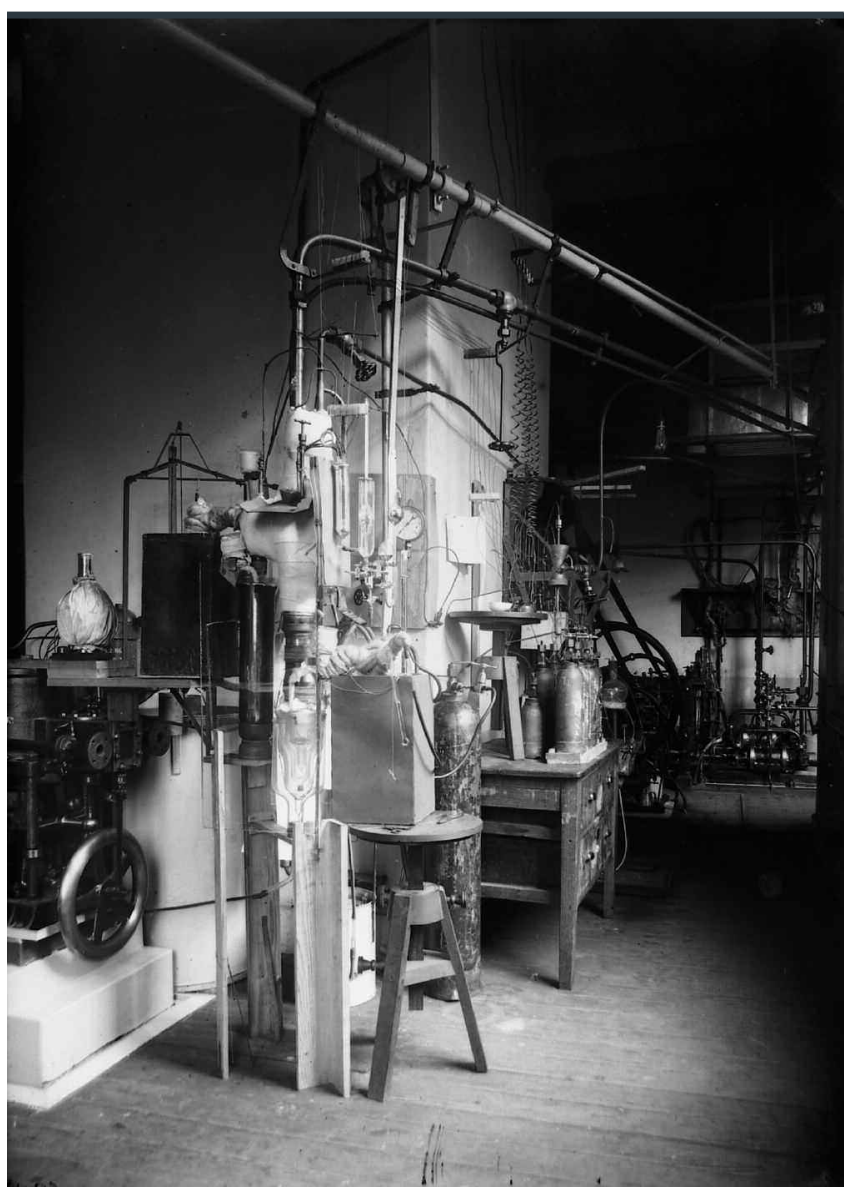




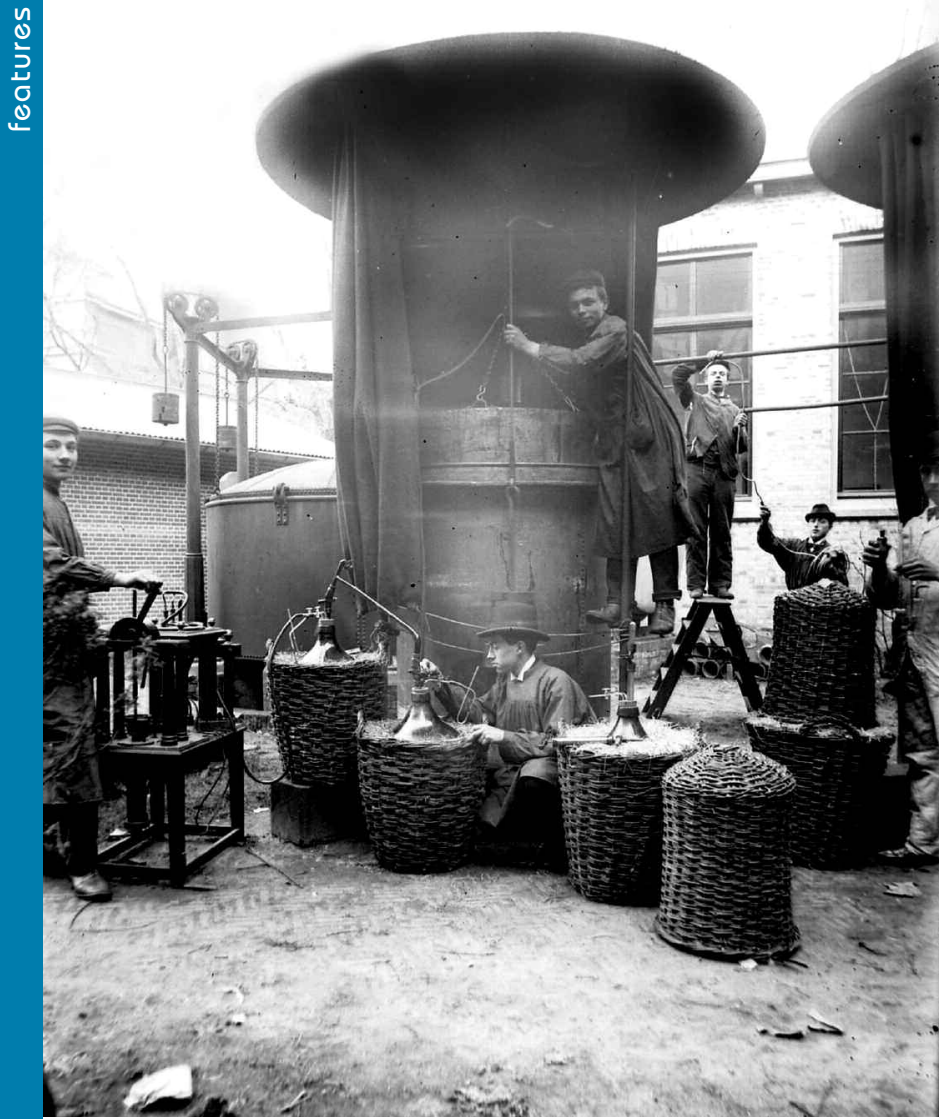

$\Delta$ FIG. 3: Pupils from the Leiden School of Instrument Makers, founded by Kamerlingh Onnes in 1901, at work with a gasholder in the garden of the Physics Laboratory. @ Photo Leiden University Institute of Physics

- 'whole'). To make matters worse, the press and trade journals, including the Globe, the Daily Telegraph, and Nature, had immediately reported the news of the 'solid helium', so that there was no alternative but to issue a full public retraction [4]. Dewar had already set the record straight in the Times, the newspaper to which he had first reported Leiden's 'triumph' after receiving the jubilant telegram.

\section{Monazite sand}

For the new attempt, Onnes was using 200 litres of helium gas, with another 160 litres in reserve - substantially more than in February. It had been extracted from thorium-bearing monazite sand, which Heike's brother Onno Kamerlingh Onnes, director of the Commercial Information Office in Amsterdam, had helped to procure in large quantities from America, by way of Hamburg. Purifying the helium gas was a particularly gruelling task, which demanded the concerted efforts of four chemists for several months. They heated the grains of sand, causing them to explode and release the gas. To eliminate impurities, they then cooled the gas with liquid air, burned it with oxygen over copper oxide, compressed it at the temperature of liquid hydrogen $\left(-253^{\circ} \mathrm{C}\right)$ and passed it over a charcoal filter. At last, on July 10 , the helium gas was finally pronounced sufficiently pure.

While the hydrogen system faithfully turned out its four litres an hour from 8.30 a.m. onwards, a pump throbbed away, creating a vacuum in the helium apparatus, and the last remaining impurities were removed from the helium gas. Liquid air was introduced into the space between the outer and inner walls of the vacuum glass vessel, after which liquid hydrogen was poured into the vessel's interior. At 2.30 p.m. it was time to start cooling the helium. Only 30 minutes later, the temperature had already fallen to $-180^{\circ} \mathrm{C}$. At 4.20 - after a worried Bé had come to check on the scientists' progress and coaxed her toiling husband into taking a few bites of a sandwich - they started up a pump to circulate the helium. An hour later, the gas was under a pressure of 100 atmospheres. The trick was to allow it to expand into a vacuum - surrounded by glasses filled with liquid hydrogen and liquid air during which its temperature would fall slightly (Joule-Thomson cooling), so that the helium flowing back would pre-cool the helium flowing in. The same principle was applied when liquefying hydrogen, but whether it would work with helium remained to be seen. Tensions were running high in lab E'.

\section{A little teacup}

They seemed to be heading for another failure. The helium thermometer was scarcely budging, and a second thermometer had given up the ghost. Then, to Onnes's relief, the temperature began to fall, and by 6.30 p.m., as the helium expanded at an accelerated rate, the temperature was already lower than that of liquid hydrogen. With fluctuations it gradually reached $-267^{\circ} \mathrm{C}$, only 6 degrees above absolute zero. Meanwhile, Onnes was down to the last flask of hydrogen, which he had just attached to the apparatus. The helium had circulated twenty times, and there was still scarcely anything to be seen besides a little swirling.

Then at $-269^{\circ} \mathrm{C}$, the thermometer suddenly started to display a remarkably stable value. That was at 7.30 p.m. What was going on? The chemist Schreinemakers, one of a series of Onnes's associates who had come to see how the experiment was going, noticed that the thermometer appeared to be standing in a bath of liquid. $\mathrm{He}$ was right. When Onnes peered at the glass containing the helium one more time, through the Dewar flasks, liquid air and liquid hydrogen, and pointed a lamp at it from an oblique angle below, he could see the surface of the liquid. The electric wires of the

$\nabla$ FIG. 4: The Leiden cascade for producing liquid oxygen and air was finished in 1894. The three cooling cycles used methyl chloride, ethylene and oxygen respectively. The hydrogen liquefier was build in 1906 . ( Photo Leiden University Institute of Physics

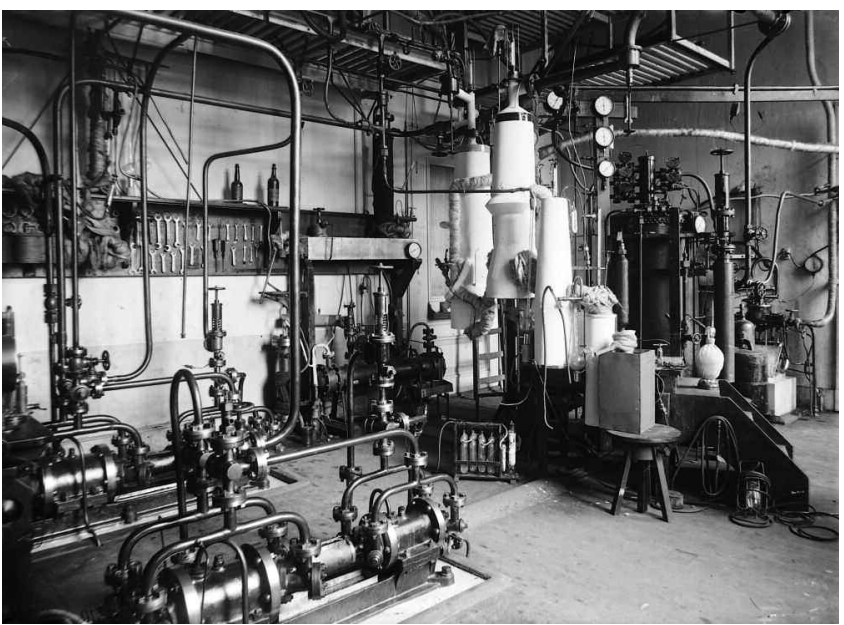


thermometer were clearly poking through it. 'After the surface had once been seen', Onnes wrote in his report for the Netherlands Academy of Arts and Sciences, 'it was no more lost sight of. It stood out sharply defined like the edge of a knife against the glass wall.'

The experiment had produced $60 \mathrm{ml}$ of liquid helium, just enough for a little teacup. As soon as the circulation was stopped, it slowly evaporated. At 8.30 p.m., when only $10 \mathrm{ml}$ of liquid was left, Onnes pumped away the vapour above the liquid in an effort to freeze the helium. Unfortunately, bringing the temperature down to about $1.5^{\circ}$ above absolute zero proved insufficient. At 9.40, with just a few millilitres of liquid helium remaining in the plant, Onnes called it a day; they had done enough. 'Not only had the apparatus been strained to the uttermost during this experiment and its preparation', he wrote in his report to the Academy, 'but the utmost had also been demanded from my assistants. But for their perseverance and their ardent devotion every item of the program would never have been attended to with such perfect accuracy as was necessary to render this attack on helium successful. In particular I wish to express my great indebtedness to Mr. G.J. Flim, who not only assisted me as chief of the technical department of the cryogenic laboratory in leading the operations, but has also superintended the construction of the apparatus according to my direction, and rendered me the most intelligent help in both respects.'

\section{Superconductivity}

Exhausted, Onnes stepped into the carriage that would take him home. Since the 'halfium' débacle still rankled in his memory, he decided against rushing to announce that he had successfully liquefied helium, choosing instead to spread the news through the Academy. By Tuesday the newspapers had heard the story from that source; Nature, deciding to be more circumspect this time, did not publish anything about it until August 13. Onnes did send word that weekend to his pupil Pieter Zeeman and mentor Johannes Diderik van der Waals, both of whom were professors in Amsterdam [5]. By chance, Van der Waals, whose theoretical work on gases and liquids had been a shining beacon to Onnes, was to give his parting lecture on Monday July 13. Onnes, who was unable to attend, could not have given him a finer leaving present. 'So I hope that although I am unable to attend your farewell ceremony, I can in this way enhance your enjoyment of this day', wrote Onnes.

The liquefaction of helium was an international milestone in experimental physics. The conquest of the final 'permanent' gas, on the $10^{\text {th }}$ of July 1908 , marked the end of an era. At the same time, it opened up a new world of low temperatures, an unexplored territory of extreme cold, full of potential surprises. Suddenly the path was clear for the discovery of superconductivity, which followed in 1911. For years, Leiden contained the coldest place on earth. In 1913 Onnes was awarded the Nobel Prize for his helium work. The Leiden Physics Laboratory remained the only institute to have produced liquid helium until 1923, even though Kamerlingh Onnes had published the full details of his method. Only after John McLennan came from Toronto to visit the Leiden helium liquefier (as a gift he brought

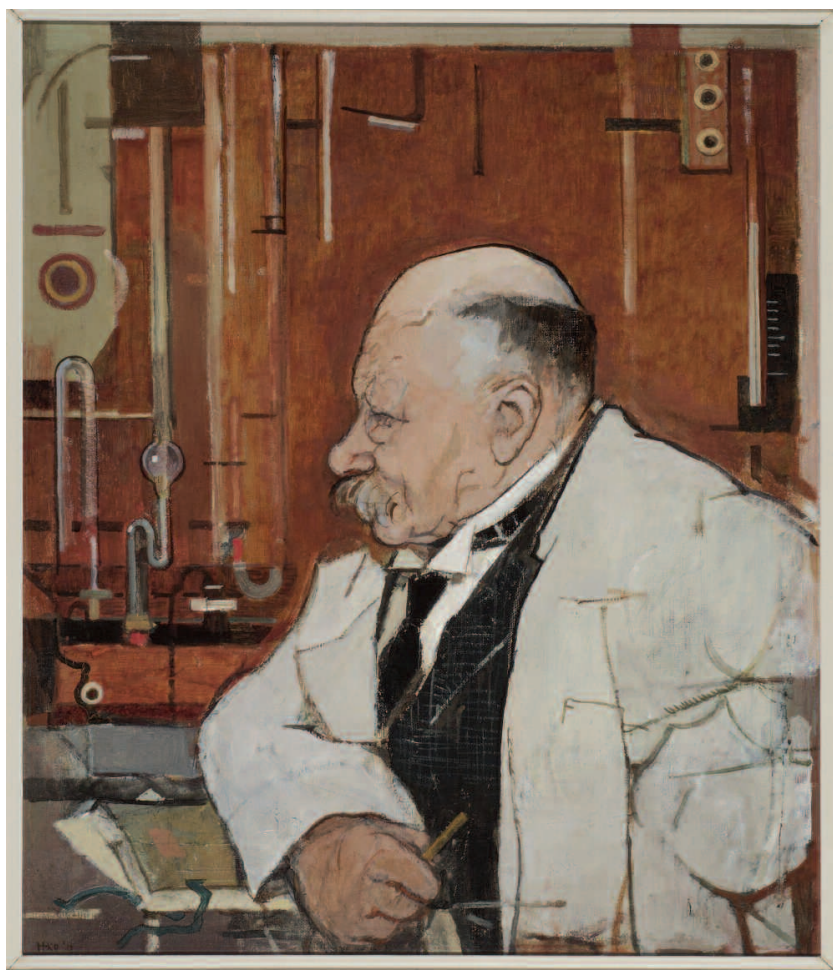

A FIG. 5: Heike Kamerlingh Onnes (1853-1926) painted in his laboratory by his nephew Harm, 1921. Oil on canvas, private collection.

from Canada a few cylinders of the precious gas), and got all the information he wanted (technical drawings included), Leiden lost its monopoly.

From 10 July 2008 until 10 May 2009 Museum Boerhaave in Leiden presents the exhibition 'The Quest for Absolute Zero'. See www.museumboerhaave.nl.

\section{About the author}

Dirk van Delft studied physics in the Kamerlingh Onnes Laboratory in Leiden. He is director of Museum Boerhaave, the Dutch National Museum for the History of Science and Medicine. He is also a professor of the history of science at Leiden University.

\section{References}

[1] Dirk van Delft, Freezing Physics. Heike Kamerlingh Onnes and the Quest for Cold (Amsterdam 2007).

[2] Details derived from H. Kamerlingh Onnes, 'The liquefaction of helium', Communications of the Physical Laboratory of the University of Leiden 108 (July 1908).

[3] Telegram from Heike Kamerlingh Onnes to Dewar, 5 March 1908, archives of the Royal Institution.

[4] The Globe, 3 March 1908; Daily Telegraph, 10 March 1908; Nature, 5 and 12 March, 16 and 23 April 1908.

[5] Heike Kamerlingh Onnes to Van der Waals, 11 July 1908, RANH, Van der Waals archives; Heike Kamerlingh Onnes to Zeeman, 12 July 1908, RANH, Zeeman archives, inv. no. 82. 